\title{
STUDY OF NANO COLLOIDAL SILICA SOL BASED PROTECTANT ON THE PREVENTION OF MASSON PINE
}

\author{
Liping Yu, Meifen Tian, Lifen Li, Zhigang Wu, Sicheng Chen, Jie Chen \\ Guizhou University \\ P.R. ChinA \\ Xuedong Xi \\ UNIVERSITY OF LORRAINE \\ FrANCE \\ (Received JANUARY 2020)
}

\begin{abstract}
In this study, wood protectants were prepared by using manganese chloride, potassium carbonate, borax and nano colloidal silica sol. Effects of the wood protectants on decay resistance, anti-mold property and fire resistance of Pinus massoniana Lamb. were discussed. The results indicated that the optimal formula of the protectant was composed of $20 \%$ colloidal silica sol and $8 \%$ modifier (manganese chloride + potassium carbonate + borax). Under this formula, the protectant had good permeability and fluidity, accompanied with synergistic effect between colloidal silica sol and modifier. Pinus massoniana Lamb. treated by the protectant with this formula showed good decay resistance, and its mass loss rates after corrosion by Gloeophyllum trabeum and Coriolus versicolor were respectively about $21 \%$ and $19 \%$, lower than those of the control group. This indicated that the preferred samples reached I-level decay resistance according to Chinese Forestry Industrial Standards LY/T 1283-2011. Moreover, Pinus massoniana Lamb. under this formula had good anti-mold property, manifested by $100 \%$ resistance to Aspergillus niger V. Tiegh and Trichoderma viride Pers. ex Fr. The treated Pinus massoniana Lamb. also showed good fire resistance with the oxygen indexes before and after leaching respectively at $20.45 \%$ and $13.64 \%$, higher than those of the control group. It was concluded that the formulated protectant of this research had not only multiple functions of one dose, but also comprehensive resistances to decay, mold and fire, as well as strong leaching resistance.
\end{abstract}

KEYWORDS: Pinus massoniana Lamb., nano colloidal silica sol, decay resistance, anti-mold resistance, oxygen index. 


\section{INTRODUCTION}

Artificial forest plantation has become an effective measure to solve supply-demand contradictions of wood for several decades. Pinus massoniana Lamb. is mainly provided by artificial forest plantation and it is the first choice of forestation in the barren mountains and it has the most extensive coverage in the mainland of China. Pine wood is highly appreciated by the furniture industry in North America, West Europe, Japan, and so on (Cheng et al. 2016, Ju et al. 2019, Wu et al. 2017, Wu et al. 2019). However, the application of Masson pine is highly restricted due to its high rosin content, easy deformation, easy blue staining, poor decay resistance and easy inflammability. Therefore, functional improvement of the woods from Pinus massoniana Lamb. is of particular importance (Hu et al. 2018, Deng et al. 2014).

Wood may be transformed into silicified wood through natural mineralization with slow penetration of natural silicates underground after millions of years. Recent researchers found that wood modification could be realized through incorporating with inorganic nanomaterials. Nano colloidal silica sol with low viscosity can penetrate into the pores of wood, and finally get a stable spatial texture, high rigidity and strong leaching resistance after the gelation and drying processes (Pries et al. 2013a,b). In addition, nano colloidal silica sol can strengthen the compatibility between the preservative and the wood because of the unique surface effect, quantum size effect and nano size effect (Jiang et al. 2018, Sun et al. 2017, Yang et al. 2017). Furthermore, nano colloidal silica sol would bring little damage to wood and can help retain the excellent environmental properties of wood to the maximum extent.

But previous studies on nano colloidal silica sol focused on the expensive raw materials such as tetraethyl orthosilicate, triethoxy silane, N-butyl titanate and tetrisopropyl titanate (GascónGarrido et al. 2016, Zhang et al. 2019), which is difficult to apply. And these silica sol generally were compounded with single chemical such as boride, nitride and so on. The heat released rate and amount of wood which was pre-impregnated with aqueous solutions of potassium carbonate and then $\mathrm{SiO}_{2}$ gels by using vacuum-press impregnation process decreased approximately $30 \%$ compared to the untreated specimens (Ye et al. 2011). But these chemicals have a prominent disadvantage for wood protection (Miyafuji and Saka 2001, Mai and Militz 2004), one single function from each chemical, which doesn't meet the modern human living demands any more. Developing a multi-functional protectant integrating decay resistance, anti-mold property and fire resistance is the main theme of wood modification. (Schwarze et al. 2003, Baldrian et al. 2008).

Manganese chloride $\left(\mathrm{MnCI}_{2}\right)$ and potassium carbonate $\left(\mathrm{K}_{2} \mathrm{CO}_{3}\right)$ are good fire retardants for wood (Chen et al. 2014, He et al. 2017). Borax $\left(\mathrm{Na}_{2} \mathrm{~B}_{4} \mathrm{O}_{7} \cdot 10 \mathrm{H}_{2} \mathrm{O}\right)$ is with good resistance to decay and mold as well as certain fire resistance (Blanchette et al. 1993, Persson et al. 2004, Wells et al. 1995, Unger et al. 2012). In this study, nano colloidal silica sol were mixed with $\mathrm{MnCI}_{2}$, $\mathrm{K}_{2} \mathrm{CO}_{3}$ and $\mathrm{Na}_{2} \mathrm{~B}_{4} \mathrm{O}_{7} \cdot 10 \mathrm{H}_{2} \mathrm{O}$ at different concentrations to prepare wood protectants. The attentions were mainly paid to the effects of protectants on decay resistance, anti-mold property and fire resistance of Pinus massoniana Lamb.

\section{MATERIALS AND METHODS}

\section{Materials}

The content and particle size of nano colloidal silica sol were $30 \pm 1 \%$ and $8-15 \mathrm{~nm}$, respectively. The silica sol was purchased from Jinghuo technology glass Co., Ltd in China. $\mathrm{MnCI}_{2}, \mathrm{~K}_{2} \mathrm{CO}_{3}$ and $\mathrm{Na}_{2} \mathrm{~B}_{4} \mathrm{O}_{7} \cdot 10 \mathrm{H}_{2} \mathrm{O}$ were all analytical pure and were purchased from Sinopharm chemical 
reagent Co., Ltd in China. Aspergillus niger V. Tiegh (AV-mold), Trichoderma viride Pers. ex Fr. (TV-mold), Coriolus versicolor. (CV-fungus) and Gloeophyllum trabeum., (GT-fungus) were applied. Pinus massoniana Lamb. tree about 25 years old were collected from Rongjiang County, Guizhou Province, locating at the South China. The test wood was a section of $2 \mathrm{~m}$ wood upward from the chest height. After drying, knotless, and normally grown sapwood (without reaction wood, decay or insect or fungal damages) materials were selected. And standard samples with different size were cut for different test indicators.

Tab. 1: The samples sizes and corresponding tests of Pinus massoniana Lamb wood.

\begin{tabular}{|l|c|c|}
\hline Sizes of wood samples $(\mathrm{L} \times \mathrm{R} \times \mathrm{T})$ & Number of each treatment & Tests indicators \\
\hline $10 \times 20 \times 20 \mathrm{~mm}$ & 24 & Decay resistance \\
\hline $50 \times 20 \times 5 \mathrm{~mm}$ & 20 & Anti-mold property \\
\hline $100 \times 10 \times 6 \mathrm{~mm}$ & 15 & Oxygen index \\
\hline
\end{tabular}

\section{Preparation of protectants}

Through the preliminary experiments, the phenomenon was be find that the doses, mixing ratio and adding sequences of different modifiers all influence homogeneity and gel time of the protectants. Through many tests of different proportions and adding sequences, $10 \%, 20 \%$ and $30 \%$ colloidal silica sol as well as aqueous solutions of mixed modifiers $\left(\mathrm{MnCl}_{2}: \mathrm{K}_{2} \mathrm{CO}_{3}\right.$ : $\mathrm{Na}_{2} \mathrm{~B}_{4} \mathrm{O}_{7} \cdot 10 \mathrm{H}_{2} \mathrm{O}=3: 2: 1$ ) with the concentrations at $4 \%, 6 \%$ and $8 \%$, were identified. The details of the mixtures were listed in Tab. 2 .

Tab. 2: Composition of nano colloidal silica sol-based protectants.

\begin{tabular}{|c|c|c|}
\hline Samples & Colloidal silica sol (\%) & Modifier (\%) \\
\hline \multirow{9}{*}{$\begin{array}{l}\text { Experimental } \\
\text { group }\end{array}$} & \multirow{3}{*}{10} & 4 \\
\hline & & 6 \\
\hline & & 8 \\
\hline & \multirow{3}{*}{20} & 4 \\
\hline & & 6 \\
\hline & & 8 \\
\hline & \multirow{3}{*}{30} & 4 \\
\hline & & 6 \\
\hline & & 8 \\
\hline
\end{tabular}

The preparation method of mixed solution was to prepare the silica sol first, and $\mathrm{K}_{2} \mathrm{CO}_{3}$ was added into the silica sol while stirring. Continue to stir until $\mathrm{K}_{2} \mathrm{CO}_{3}$ was completely dissolved. Then $\mathrm{Na}_{2} \mathrm{~B}_{4} \mathrm{O}_{7} \cdot 10 \mathrm{H}_{2} \mathrm{O}$ was add and a certain amount of phosphoric acid was also added immediately. When the $\mathrm{Na}_{2} \mathrm{~B}_{4} \mathrm{O}_{7} \cdot 10 \mathrm{H}_{2} \mathrm{O}$ was completely dissolved, $\mathrm{MnCl}_{2}$ was added finally, and then the mixture were stirred for about half an hour for better dissolved.

\section{Treatments of Pinus massoniana Lamb. wood}

Wood samples were dried in an oven (101-1AB electric blast drying oven) at $100^{\circ} \mathrm{C} \pm 5^{\circ} \mathrm{C}$ until reaching constant weights and then moved out and stored in glass drier to cool down to the room temperature, weighted and then put in vacuum chamber. The protectants were poured into the chamber until $5 \mathrm{~cm}$ higher than the surface of the piles of wood samples under vacuum conditions (-0.09 MPa, $30 \mathrm{~min})$. Next, the samples were taken out and the surface liquids of each 
wood sample was removed gently by a piece of filter paper. The wood samples were put in indoor environment for about one week to assure full penetration and fixation of protectants and then dried to the constant weight in an oven at $100^{\circ} \mathrm{C}$. Subsequently, the samples were conditioned at $25^{\circ} \mathrm{C}$ and $60 \%$ relative humidity $(\mathrm{RH})$ for one week.

To discuss the leaching resistance of the protectants in wood samples., leaching test was implemented with reference to the standard AWPA E11-12. Specifically, the wood samples were immersed completely in distilled water and then sealed up with a piece of protectant film. Next, it was put in a constant-temperature oscillator for two weeks of oscillating loss. Time interval was set 6 h, 24 h, 48 h and water was changed every 18 h.

\section{Decay resistance test}

Decay resistance of Pinus massoniana Lamb. was tested with references to Chinese forestry industrial standards LY/T 1283-2011 Laboratory fungal toxicity test of wood preservative. Specifically, the culture media were prepared with river sand, saw dust and maltose. Poplar wood was put on the surface as the feeding wood and applied with wood- rotting fungi and then was conditioned at $28^{\circ} \mathrm{C}$ and $80 \% \mathrm{RH}$ for 2 weeks. Test samples were sterilized and then put on the feeding wood for another 12 weeks after wood-rotting fungi cover the whole the culture medium. Next, samples were taken out and surface impurities were removed. The mass loss rate after corrosion was calculated by the following formula:

$$
\mathrm{L}=\frac{M 1-M 2}{M 1} \times 100 \%
$$

where: $\mathrm{L}$ is the mass loss rate (\%),

M1 is the constant mass before corrosion of samples $(\mathrm{g})$,

M2 is the constant mass after corrosion of samples $(\mathrm{g})$.

According to standards LY/T 1283-2011, the corrosion strength is evaluated the I-level if the mass loss rate is within $0-10 \%$, II-level in 11-24\%, III-level in $24-44 \%$ and zero decay resistance for $>45 \%$.

\section{Anti-mold property test}

Anti-mold property was tested with reference to GB/T 18261-2013 Test method of mold and blue stain fungi of wood after mildew preventive treatment. The details are introduced as follows. Potato agar medium was poured into a culture dish and mold was input into the culture medium after it was cooled, which was conditioned at $28^{\circ} \mathrm{C}$ and $80 \% \mathrm{RH}$ for 1 week. After mold covered the whole medium surface, two pieces of glass rods with a diameter of $3 \mathrm{~mm}$ were put on the surface of culture medium. Meanwhile, samples were put on the glass rods after sterilized and cultured for another 4 weeks. Samples were taken out to observe mold infection. The anti-mold effect was determined according to infection area.

\section{Fire resistance test}

With references to GB/T 2406.2-2009 Oxygen index test of combustion behaviors of plastics, oxygen index was tested by a TTech-GBT2406-2 intelligent oxygen index analyzer. 


\section{RESULTS AND DISCUSION}

\section{Decay resistance of Pinus massoniana Lamb.}

Results of decay resistance of Pinus massoniana Lamb. after 12 weeks of corrosion by GT-fungus and CV-fungus were shown in Tab. 3, Fig. 1 and Fig. 2.

Tab. 3: Results of decay resistance of Pinus massoniana Lamb.

\begin{tabular}{|c|c|c|c|c|c|c|}
\hline \multirow{2}{*}{ Samples } & \multirow{2}{*}{$\begin{array}{c}\text { Colloidal } \\
\text { silica sol (\%) }\end{array}$} & \multirow{2}{*}{$\begin{array}{l}\text { Modifier } \\
\text { (\%) }\end{array}$} & \multicolumn{2}{|c|}{$\begin{array}{c}\text { Mass loss after corrosion by } \\
\text { GT-fungus }(\%)\end{array}$} & \multicolumn{2}{|c|}{$\begin{array}{c}\text { Mass loss after corrosion by } \\
\text { CV-fungus (\%) }\end{array}$} \\
\hline & & & $\begin{array}{l}\text { Without } \\
\text { leaching }\end{array}$ & $\begin{array}{l}\text { Leaching } \\
\text { treatment }\end{array}$ & $\begin{array}{l}\text { Without } \\
\text { leaching }\end{array}$ & $\begin{array}{c}\text { Leaching } \\
\text { treatment }\end{array}$ \\
\hline Control group & 0 & 0 & $28.51 \pm 0.64$ & $29.27 \pm 0.65$ & $26.72 \pm 0.71$ & $29.89 \pm 0.63$ \\
\hline \multirow{9}{*}{$\begin{array}{l}\text { Experimental } \\
\text { group }\end{array}$} & \multirow{3}{*}{10} & 4 & $19.81 \pm 0.53$ & $20.71 \pm 0.62$ & $21.15 \pm 0.66$ & $22.37 \pm 0.62$ \\
\hline & & 6 & $18.11 \pm 0.51$ & $19.69 \pm 0.79$ & $15.21 \pm 0.61$ & $16.01 \pm 0.51$ \\
\hline & & 8 & $16.42 \pm 0.36$ & $21.01 \pm 0.42$ & $10.75 \pm 0.37$ & $13.78 \pm 0.29$ \\
\hline & \multirow{3}{*}{20} & 4 & $10.42 \pm 0.39$ & $15.84 \pm 0.33$ & $12.36 \pm 0.21$ & $13.94 \pm 0.38$ \\
\hline & & 6 & $7.31 \pm 0.15$ & $9.51 \pm 0.31$ & $7.98 \pm 0.14$ & $9.70 \pm 0.32$ \\
\hline & & 8 & $7.19 \pm 0.13$ & $8.33 \pm 0.27$ & $7.84 \pm 0.02$ & $8.26 \pm 0.120$ \\
\hline & \multirow{3}{*}{30} & 4 & $13.34 \pm 0.87$ & $16.78 \pm 0.61$ & $14.83 \pm 0.35$ & $16.97 \pm 0.42$ \\
\hline & & 6 & $10.90 \pm 0.57$ & $12.20 \pm 0.52$ & $13.88 \pm 0.45$ & $18.17 \pm 0.79$ \\
\hline & & 8 & $7.80 \pm 0.41$ & $11.17 \pm 0.84$ & $9.66 \pm 0.49$ & $16.57 \pm 0.84$ \\
\hline
\end{tabular}

The mass loss rate of the control group was nearly $30 \%$, which basically belonged to the II-level decay resistance. Although Pinus massoniana Lamb. which was treated by protectants had certain mass losses no matter whether it undergone leaching treatment or not, the mass loss rate was far lower than that of the control group. This result proved that the colloidal silica sol-based protectant could improve decay resistance of Pinus massoniana Lamb. significantly. Mass loss rate of samples after leaching treatment was slightly higher than that of control group, indicating that this protectant had good leaching resistance and it could be fixed inside wood to protect it for a long period. So, this protectant is applicable in outdoor environment.

Same analysis as the former, samples without leaching treatment under corrosion by GT-fungus reached the II-level. The minimum mass loss rate was achieved by the protectant formula of $20 \%$ colloidal silica sol $+8 \%$ modifier, which was only $7.19 \%$ and reached the I-level. Samples after leaching treatment basically reached the II-level except for the formula of $10 \%$ colloidal silica sol $+4 \%$ modifier. Similarly, the minimum $(8.33 \%)$ was attributed to the formula of $20 \%$ colloidal silica sol $+8 \%$ modifier, which also reached the I-level.

Samples without leaching treatment under corrosion by CV-fungus reaching the II-level except for the formula of $10 \%$ colloidal silica sol $+4 \%$ modifier. The minimum mass loss rate was achieved by the protectant formula of $20 \%$ colloidal silica sol $+8 \%$ modifier, which was only $7.84 \%$ and reached the I-level. Samples after leaching treatment basically reached the II-level except for the formula of $10 \%$ colloidal silica sol $+4 \%$ modifier. Similarly, the minimum mass loss rate $(8.26 \%)$ was attributed to the formula of $20 \%$ colloidal silica sol $+8 \%$ modifier, which also reached the I-level.

According to comparison of Tab. 1, Fig. 1 and Fig. 2, the best decay resistance of Pinus massoniana Lamb. was achieved when the concentration of colloidal silica sol was $20 \%$, followed by that when the concentration of colloidal silica sol was $30 \%$. 


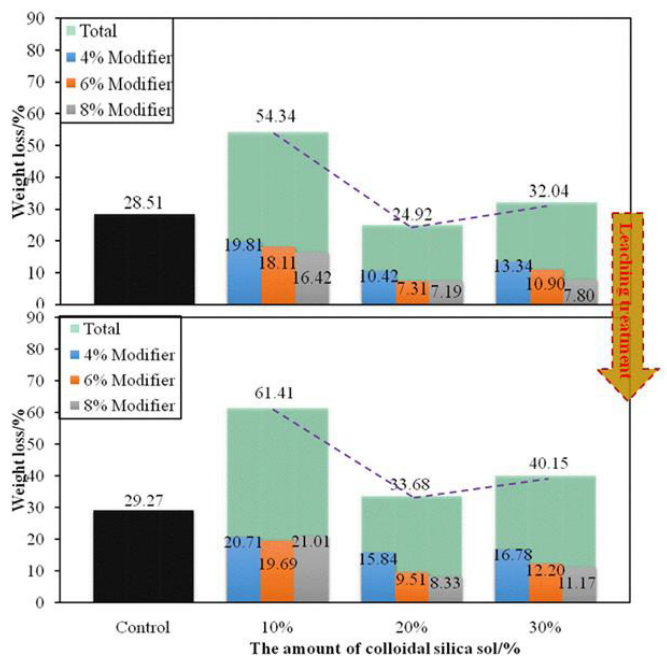

Fig. 1: Preservative effect of Pinus massoniana Lamb. for GT-fungus.

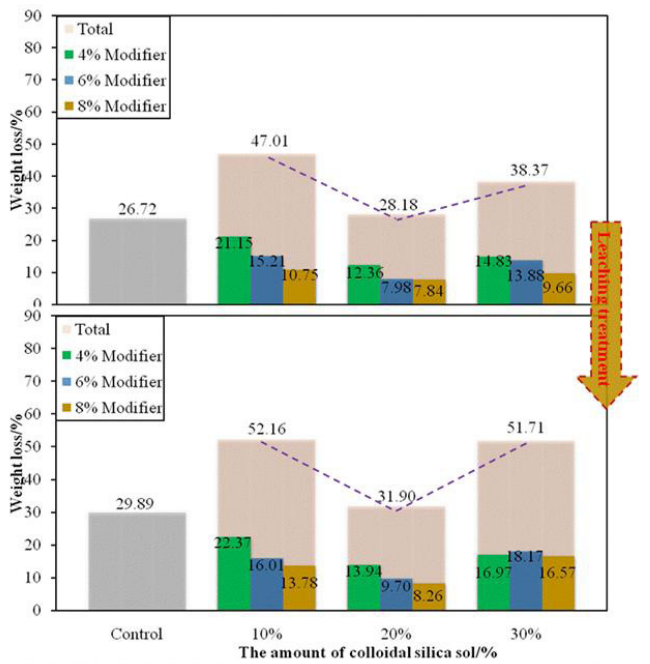

Fig. 2: Preservative effect of Pinus massoniana Lamb. for CV-fungus.

The Pinus massoniana Lamb. showed the poorest decay resistance when the concentration of colloidal silica sol was $10 \%$. Given a low concentration of colloidal silica sol, the total effective amount of protectant penetrating into wood was low, thus resulting in the poorest decay resistance when the concentration of colloidal silica sol was $10 \%$. On contrary, the viscosity of the protectant increased with the increase of concentration of colloidal silica sol. As a result, protectant was difficult to penetrate into wood, which could influence decay resistance and fixation effect. This explained the maximum reduction of decay resistance of Pinus massoniana Lamb. after leaching treatment. 
To sum up, Pinus massoniana Lamb. achieved the best decay resistance to GT-fungus and CV-fungus when the concentration of colloidal silica sol was $20 \%$. In particular, the decay resistance under the formulas of $20 \%$ colloidal silica sol $+8 \%$ modifier and $20 \%$ colloidal silica sol $+6 \%$ modifier reached I-level.

\section{Anti-mold property of Pinus massoniana Lamb.}

The results of anti-mold resistance of Pinus massoniana Lamb. under corrosion of AV-mold and TV-mold were shown in Tab. 4, Fig. 3 and Fig. 4.

Tab. 4: Results of anti-mold property of Pinus massoniana Lamb.

\begin{tabular}{|c|c|c|c|c|c|c|}
\hline \multirow{3}{*}{ Samples } & \multirow{2}{*}{$\begin{array}{c}\text { Colloidal } \\
\text { silica sol (\%) }\end{array}$} & \multirow{2}{*}{$\begin{array}{c}\text { Modifier } \\
\text { (\%) }\end{array}$} & $\begin{array}{c}\text { Damaged } \\
\text { degree }\end{array}$ & $\begin{array}{c}\text { Anti-mold } \\
\text { property (\%) }\end{array}$ & Samples & $\begin{array}{c}\text { Colloidal } \\
\text { silica sol (\%) }\end{array}$ \\
\cline { 4 - 7 } & & AV-mold & TV-mold & AV-mold & TV-mold \\
\hline Control group & 0 & 0 & 1.5 & 1.25 & 0 & 0 \\
\hline \multirow{4}{*}{$\begin{array}{c}\text { Experimental } \\
\text { group }\end{array}$} & \multirow{3}{*}{10} & 4 & 0.5 & 0.25 & 66.67 & 80 \\
\cline { 3 - 7 } & & 6 & 0.25 & 0.50 & 83.33 & 60 \\
\cline { 3 - 7 } & \multirow{3}{*}{20} & 8 & 0.25 & 0 & 91.67 & 100 \\
\cline { 3 - 7 } & & 4 & 0.25 & 0.25 & 83.33 & 80 \\
\cline { 3 - 7 } & \multirow{3}{*}{30} & 8 & 0 & 0.25 & 100 & 90 \\
\cline { 3 - 7 } & & 4 & 0 & 0 & 100 & 100 \\
\cline { 3 - 7 } & & 8 & 0.25 & 0.25 & 83.33 & 90 \\
\hline
\end{tabular}

The control presented zero anti-mold resistance. After protectant treatment, the AV-mold resistance of Pinus massoniana Lamb. reached 66.67 100\% and that of TV-mold was 60 100\%. These demonstrated the significant improvement of anti-mold resistance of Pinus massoniana Lamb. with the protectant. The best anti-AV-mold resistance result (100\%) was achieved under $20 \%$ colloidal silica sol $+6 \%$ modifier and $20 \%$ colloidal silica sol $+8 \%$ modifier. The best antiTV-mold resistance (100\%) was achieved under 10\% colloidal silica sol $+8 \%$ modifier and $20 \%$ Colloidal silica sol $+8 \%$ modifier.

When the concentration of colloidal silica sol was $20 \%$, Pinus massoniana Lamb. presented the best resistances to $\mathrm{AV}$-mold and $\mathrm{TV}$-mold. The comprehensive anti-mold results to $\mathrm{AV}$-mold and TV-mold were similar, which was $283.33 \%$ and $270 \%$, respectively. When the concentration of colloidal silica sol was $10 \%$ and 30\%, the comprehensive anti-mold resistance of Pinus massoniana Lamb. was slightly lower than that of the concentration was $20 \%$. Changes of concentration of colloidal silica sol influenced anti-mold resistance less than decay resistance. This indicated the outstanding control efficiency of this protectant for mildew. 


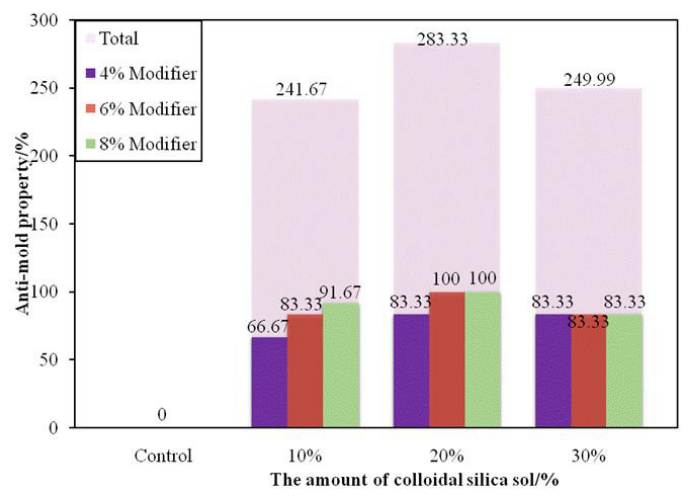

Fig. 3: Anti-mold effect of Pinus massoniana Lamb. for AV-mold.

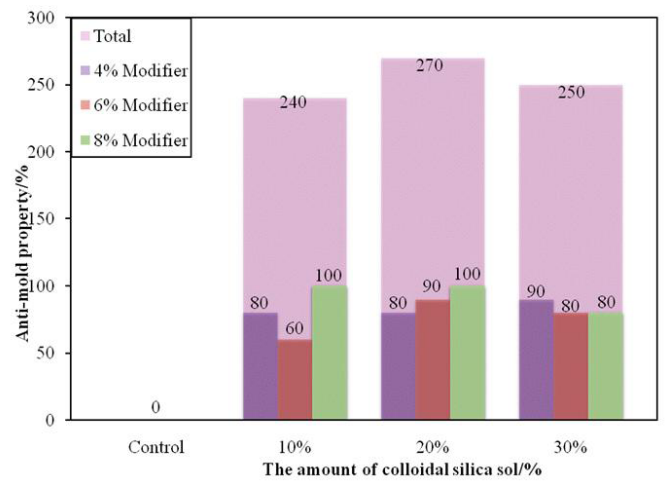

Fig. 4: Anti-mold effect of Pinus massoniana Lamb. for $T V$-mold.

\section{Fire resistance of Pinus massoniana Lamb.}

Fire resistance is generally measured by oxygen index (Hashim et al. 2005, Xu et al. 2017, Zhou et al. 2018). Oxygen index refers to the minimum oxygen concentration to maintain combustion of wood. The lower the oxygen index is, the easier the combustion will be. On contrary, the higher oxygen index implies the higher difficulties of combustion (Yasar 2019, Uner et al. 2016). Generally, timber materials are viewed as difficult to be combusted when the oxygen index is higher than $32 \%$.

Results of oxygen index under combustion of Pinus massoniana Lamb. were shown in Tab. 5 and Fig. 5. 
Tab. 5: Combustion oxygen index of Masson pine.

\begin{tabular}{|c|c|c|c|c|}
\hline \multirow{2}{*}{ Samples } & \multirow{2}{*}{ Silica sol (\%) } & \multirow{2}{*}{ Modifier (\%) } & \multicolumn{2}{|c|}{ Oxygen index (\%) } \\
\cline { 3 - 5 } & & & Without leaching & Without leaching \\
\hline Control group & 0 & 0 & $27.61 \pm 1.67$ & $27.61 \pm 1.67$ \\
\hline \multirow{4}{*}{$\begin{array}{c}\text { Experimental } \\
\text { group }\end{array}$} & \multirow{3}{*}{20} & 4 & $44.16 \pm 1.38$ & $34.62 \pm 3.60$ \\
\cline { 3 - 5 } & & 6 & $47.8 \pm 2.39$ & $40.84 \pm 0.82$ \\
\cline { 3 - 5 } & \multirow{3}{*}{20} & 8 & $51.36 \pm 4.34$ & $42.28 \pm 0.71$ \\
\cline { 3 - 5 } & & 4 & $50.32 \pm 2.90$ & $42.28 \pm 0.37$ \\
\cline { 3 - 5 } & \multirow{3}{*}{30} & 8 & $51.62 \pm 1.02$ & $41.94 \pm 0.49$ \\
\cline { 3 - 5 } & & 4 & $64.86 \pm 3.05$ & $46.80 \pm 0.82$ \\
\cline { 3 - 5 } & & 6 & $51.56 \pm 4.13$ & $33.52 \pm 0.83$ \\
\cline { 3 - 5 } & & 8 & $51.28 \pm 1.53$ & $33.16 \pm 0.35$ \\
\hline
\end{tabular}

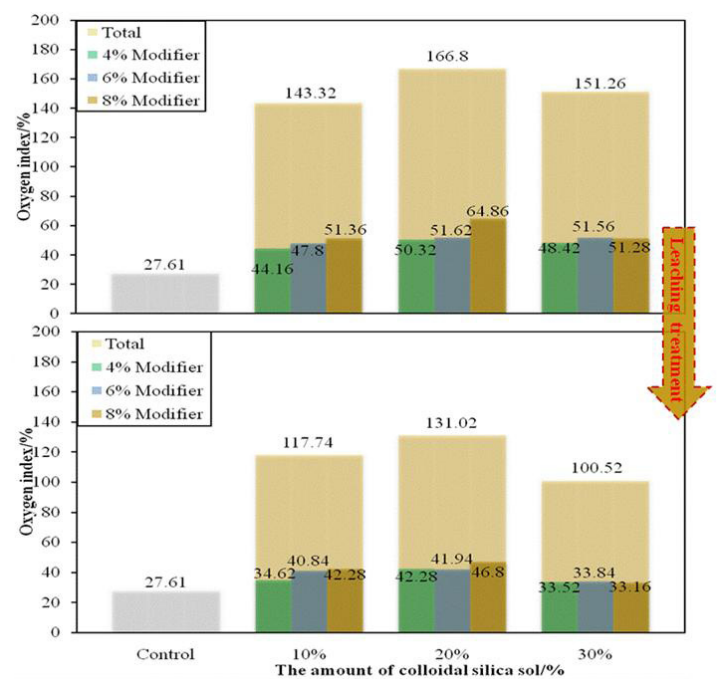

Fig. 5: Fire resistance effect of Pinus massoniana Lamb. under colloidal silica sol-based protectant.

The oxygen index of the control group was $27.61 \%$, indicating that Pinus massoniana Lamb. without application of protectant was inflammable. Oxygen index was higher than that of the control group and was significantly higher than 32\% no matter whether it had received leaching treatment or not, indicating that the protectant can improve fire resistance of Pinus massoniana Lamb. Samples treated by the protectant basically became difficult to be combusted. Oxygen index of samples after leaching treatment decreased slightly compared with the control group. It proved that this protectant had strong leaching resistance and reliable fire resistance.

Oxygen index of samples without leaching treatment reached the maximum (64.86\%) under $20 \%$ colloidal silica sol $+8 \%$ modifier, while the oxygen index of samples with leaching treatment also reached $46.80 \%$ under $20 \%$ colloidal silica sol $+8 \%$ modifier. In a word, $20 \%$ colloidal silica sol $+8 \%$ modifier was the best formula. 
It can be seen from Fig. 5 that with the increase of modifier concentration, the oxygen index increases gradually. This was because modifier influenced the actual effective content of protectant and it determined the fire resistance. With the increase of concentration of colloidal silica sol, the oxygen index increased firstly and then decreased, because high concentration colloidal silica sol influenced penetration of protectant in wood. This demonstrated that there was certain collaborative effect between colloidal silica sol and modifier if solubility of colloidal silica sol may not influence penetration and flow of the protectant system.

\section{CONCLUSIONS}

The application of Masson pine is restricted due to the disadvantages of inflammability, easy mildew and poor decay resistance. Wood protectants were prepared by using manganese chloride, potassium carbonate, borax and nano colloidal silica sol in this study. Influences of the protectant on decay resistance, anti-mold property and fire resistance of Pinus massoniana Lamb. were studied. The results indicated that: (1) The colloidal silica sol-based protectant had multiple functions, including decay resistance, anti-mold resistance and fire resistance. Especially, it had outstanding anti-mold resistance and good leaching resistance. (2) The best formula of the protectant was $20 \%$ colloidal silica sol $+8 \%\left(\mathrm{MnCl}_{2}+\mathrm{K}_{2} \mathrm{CO}_{3}+\mathrm{Na}_{2} \mathrm{~B}_{4} \mathrm{O}_{7} \cdot 10 \mathrm{H}_{2} \mathrm{O}\right)$. Under this formula, the protectant had good penetration and liquidity, accompanied with synergistic effect between colloidal silica sol and modifier. (3) The Pinus massoniana Lamb. which was treated by the best formula of protectant showed good decay resistance and its mass loss rates after corrosion by Gloeophyllum trabeum and Coriolus versicolor were respectively about $21 \%$ and $19 \%$, lower than those of the control group. This indicated that the preferred samples reached I-level decay resistance according to Chinese Forestry Industrial Standards LY/T 1283-2011. Pinus massoniana Lamb. under this formula had good anti-mold property, manifested by $100 \%$ resistance to Aspergillus niger V. Tiegh and Trichoderma viride Pers. ex Fr. (4) The treated Pinus massoniana Lamb. also showed good fire resistance with the oxygen indexes before and after leaching respectively at $20.45 \%$ and $13.64 \%$, higher than those of the control group. It was concluded that the formulated protectant of this research had not only multiple functions of one dose, but also comprehensive resistances to decay, mold and fire, as well as strong leaching resistance.

\section{ACKNOWLEDGMENTS}

This work was supported by Science and technology project of Guizhou Province (No. NY[2015]3027, Science-technology Support Foundation of Guizhou Province of China (No. [2019]2308, [2019]2325 and [2020]1Y125), Forestry Department Foundation of Guizhou Province of China (No. [2017]14 and [2018]13).

\section{REFERENCES}

1. Blanchette, R.A., Zabel, R.A., Morrell, J.J., 1993: Wood microbiology: Decay and its prevention. Mycologia 85(5): 874.

2. Baldrian, P., Valášková, V., 2008: Degradation of cellulose by basidiomycetous fungi. FEMS Microbiology Reviews 32(3): 501-521. 
3. Chen, X., Yuan, L.P., Hu, Y.C., Tian, L.C., Xia, L.Y., 2014: Comparative study on the flame retarding and smoke suppressing properties of wood treated by manganese compounds. Journal of Functional Materials 45(11): 11076-11080.

4. Cheng, X.Y., Li, X.J., He, X., Li, Y., Xiong, X.Y., Xie, J., Quan, P., 2016: Effects of the superheated steam temperature on the drying rate and mechanical properties of Masson pine wood. Journal of Forestry Engineering 1(6): 51-57.

5. Deng, X.W., Zhang, L.Y., Lei, P.F., Xiang, W.H., Yan, W.D., 2014: Variations of wood basic density with tree age and social classes in the axial direction within Pinus massoniana stems in Southern China. Annals of Forest Science 71(4): 1-12.

6. Gascón-Garrido, P., Thévenon, M.F., Mainusch, N., Militz, H., Viöl, W., Mai, C., 2017: Siloxane-treated and copper-plasma-coated wood: Resistance to the blue stain fungus Aureobasidium pullulans and the termite Reticulitermes flavipes. International Biodeterioration \& Biodegradation 120: 84-90.

7. He, S., Wu, W., Zhang, M., Qu, H., Xu, J., 2017: Synergistic effect of silica sol and $\mathrm{K}_{2} \mathrm{CO}_{3}$ on flame-retardant and thermal properties of wood. Journal of Thermal Analysis \& Calorimetry 128(2): 825-832.

8. Hu, L., Xu, H.L., Tan, J.H., Yang, Z.Q., 2018: Research progress in wood property characteristic of masson pine and its processing and utilization. World Forestry Research 31(1): 40-45.

9. Hashim, R., How, L., Kumar, R., Sulaiman, O., 2005: Some of the properties of flame retardant medium density fiberboard made from rubberwood and recycled containers containing aluminum trihydroxide. Bioresource Technology 96(16): 1826-1831.

10. Jiang, J., Cao, J., Wang, W., 2018: Characteristics of wood-silica composites influenced by the $\mathrm{pH}$ value of silica sols. Holzforschung 72(4): 311-319.

11. Ju, S., Li, X.C., Luo, T.F., Li, M., 2019: Anisotropic propagation of acoustic emission signal on surface of Pinus massoniana Lamb. Glulam. Journal of Forestry Engineering 4(2): 48-53.

12. Justine, M.F., Yang, W.Q., Wu, F.Z., Khan, M.N., 2017: Dynamics of biomass and carbon sequestration across a chronosequence of Masson pine plantations. Journal of Geophysical Research 122(3): 578-591.

13. Li, Y., Yao, Q.Z., Xing, Z., Wu, C.F., Zhang L.Q., 2018: Responses of endophytic microbial community in Masson pine to the early stage of pine wilt disease. Research \& Reviews: Journal of Botanical Sciences 7(2): 61-69.

14. Mai, C., Militz, H., 2004: Modification of wood with silicon compounds. Treatment systems based on organic silicon compounds? A review. Wood Science and Technology 37(6): 453-461.

15. Miyafuji, H., Saka, S., 2001: $\mathrm{Na}_{2} \mathrm{O}-\mathrm{SiO}_{2}$ wood-inorganic composites prepared by the solgel process and their fire-resistant properties. Journal of Wood Science 47(6): 483-489.

16. Persson, P.V., Hafrén, J., Fogden, A., Daniel, G., Iversen, T., 2004: Silica nanocasts of wood fibers: A study of cell-wall accessibility and structure. Biomacromolecules 5(3): 1097-1101.

17. Pries, M., Mai, C., 2013a: Fire resistance of wood treated with a cationic silica sol. European Journal of Wood and Wood Products 71(2): 237-244.

18. Pries, M., Mai, C., 2013b: Treatment of wood with silica sols against attack by wooddecaying fungi and blue stain. Holzforschung 67(6): 697-705.

19. Schwarze, F., Fink, S., Deflorio, G., 2003: Resistance of parenchyma cells in wood to degradation by brown rot fungi. Mycological Progress 2(4): 267-274.

20. Sun, F.L., Prosper, N.K., Wu, H.P., Qian, J.J., Yang, X.S., Rao, J., Guo, M., 2017: A review on the development of wood and bamboo preservation. Journal of Forestry Engineering 2(5): 1-8. 
21. Ye, Q.Q. Lai, J.Y., Qian, X.Q. Xia, X.Q. Ruan, H., Wu, X.Q., Zhao, Y.F., 2011: Research on fire retardant performance of wood with the compound of potassium carbonate and $\mathrm{SiO}_{2}$ gels. New building materials 38(9): 24-27.

22. Yasar, S.S. 2019: Effects of wood preservatives on the combustion process and combustion quality of wood. Wood Research 64(1): 59-70.

23. Unger, B., Bücker, M., Reinsch, S., Hübert, T., 2012: Chemical aspects of wood modification by sol-gel-derived silica. Wood Science and Technology 47(1): 83-104.

24. Uner, I.H., Deveci, I., Baysal, E., Turkoglu, T., Toker, H., Peker, H., 2016: Thermal analysis of Oriental beech wood treated with some borates as fire retardants. Wood Research 18(2): 293-304.

25. Wang, X.Z., Chen, X.Q., Wu, Y., Zhao, L.G., Li, Y.J., Wang, S.Q. 2018: Effects of thermal modification on the physical, chemical and micromechanical properties of Masson pine wood (Pinus massoniana Lamb.). Holzforschung 72(12): 1063-1070.

26. Wells, J.M., Boddy, L., 1995: Effect of temperature on wood decay and translocation of soil-derived phosphorus in mycelial cord systems. New Phytologist 129(2): 289-297.

27. Wu, W.J., Jiang, B., Yang, L.F., Jin, Y.C., 2017: Isolation of lignin from Masson pine by liquid-liquid extraction based on complete dissolution in $\mathrm{NaOH}$ aqueous solution. Bioresources 13(1): 231-240.

28. Wu, Z.G., Chen, S.C., Tian, M.F., Li, L.F., Yu, L.P., Xi, X.D., Liang, J.K., Zhang, B.G., Lei, H., 2019: Effects of heat-treatment on bonding performance of Betula alnoides. Wood Research 64(6): 1045-1054.

29. Xu, B., Li, W., Tu, D., Wu, Z., Song, C., 2017: Effects of nitrogenphosphorus flame retardants in different forms on the performance of slim-type medium-density fiberboard. Bioresources 12(4): 8014-8029.

30. Yang, D.M., Wang, H., Li, S.J., Yuan, H.J., 2017: Decay and mould resistance of cinnamaldehyde and its derivatives. Journal of Forestry Engineering 2(1): 46-50.

31. Zhou, Z.X., Yao, X.L., Du, C.G., Yu, H.L., Huang, Q., Liu, H.Z., 2018: Effect of hygroscopicity of fire retardant on hygroscopicity of fire retardant bamboo chips. Wood Research 63(3): 373-382.

32. Zhang, J., Gao, J.J., Yu, L.L., Zhu, L.Z., Ma, X.J., 2019: Dimensional stability of nano$\mathrm{SiO}_{2}$ /emulsified wax modified $\mathrm{Cu}$ Az-treated wood after one year outdoor exposure test. Wood Research 64(6): 965-974.

\author{
Liping Yu, Meifen Tian, Lifen Li, Zhigang Wu*, Sicheng Chen, Jie Chen \\ Guizhou University \\ College of Forestry \\ Guiyang 550025 \\ Guizhou \\ P.R. CHINA \\ *Corresponding author: wzhigang9@163.com
}

\author{
Xuedong Xi \\ University OF LORRAINE \\ ENSTIB-LERMAB 8805I \\ EPINAL \\ FRANCE
}

